Calcul opérationnel

Par Édouard Labin. (Abrégé théorique et pratique de mathématiques supérieures.) Pp. iv + 150. (Paris : Masson et Cie., 1949.) 780 francs.

$\mathrm{T}$ HE Laplace transform has a large literature, ranging from severely abstract studies of the theory to manuals of rules and recipes for the manipulator, as far as these are required for the solution of technological problems. For adding to this collection, M. Edouard Labin gives the reason that his precise objective is not attained by any of the existing books. His treatment is not to be one in which the mathematician can find flaws, nor is it to be centred on physical problems. He wishes to give a brief, accurate and comprehensive account of the topic in a form suitable for those who wish to acquire it for use, whether in other branches of mathematics, or in other fields of science, assuming these readers to have a sound knowledge of integral calculus and analysis.

To this end, M. Labin rejects the closely woven deductive style of the "Cours d'Analyse", and instead, for example, he frames the enunciations of theorems as answers to the sort of question the user is likely to ask rather than as stages in an abstract mathematical formulation; he is content with explanations instead of demonstrations, leaving the reader to supply details or look them up elsewhere. In order that this scheme should not reduce to merely another collection of recipes, he uses the resources of ideographs, diagrams, tabulated matter and the emphasis of lavish italic and Clarendon type. There are nine sections on the theory of the method. The remaining four show, without examples, how it can be applied to ordinary and partial differential equations, integral equations and difference equations.

The student would probably be well advised to acquire a general acquaintance with the main ideas of the Laplace technique from one of the many semipopular accounts before turning to this book to fill in the gaps.

\section{Elementary Principles of Statistics}

By A. C. Rosander. Pp. $\mathrm{x}+693$. (New York: D. Van Nostrand Co., Inc.; London: Macmillan and Co., Ltd., 1951.) $45 s$, net.

MR. ROSANDER states an intention of giving a 1 non-mathematical introduction to the science of statisties. Unfortunately he shows no evidence of having one of the two motives that would justify this intention: to say something new, or to present standard material in a new way. Without originality or inspiration, his thirty-six chapters pursue the long and long-familiar trail, from elementary ideas and descriptive properties of frequency distributions to sampling theory, analytical techniques and significance tests for scientific data, and methods of inductive inference.

The presentation of general statistical principles, in the early part of the book, is sound, though it contains little that has not been said as well before. To the reader of very restricted mathematical knowledge, the argument will often seem too mathematical, yet the dogmatic assertions of formulæ for various distributions and estimations will be completely unsatisfying to a mathematician. The author would have better fulfilled his purpose had he explained the meaning and logical structure of the methods rather than rested content with displaying algebraic formulæ. Instead, though actually erroneous statements seem fow, the misleading impressions sometimes created suggest that he is imperfectly acquainted with many of the procedures he describes in the later chapters. Many examples, of which the best have been taken from other publications, are fully worked, but with little critical explanation of the reasons for choosing certain methods and the limitations on their use. For his own contribution to illustrative examples, Mr. Rosander has relied far too much on fictitious data, though he has presented some interesting experimental and observational material (especially as exercises for the reader). $\quad$ D. J. FInNEX

\section{The Identification of Molecular Spectra}

By Prof. R. W. B. Pearse and Dr. A. G. Gaydon. Second edition, revised. Pp. xi+276+12 plates. (London: Chapman and Hall, Ltd., 1950.) 50s. net.

7 HIS book is so well known that its scope and contents require no discussion. The value of such a compilation does, however, tend rapidly to depreciate unless, periodically, a now edition is prepared incorporating the more recent advances in the particular field. During the ten years since this book first appeared, many valuable additional data have been obtained, and the second edition therefore makes a most welcome and timely appearance. To incorporate all these new data without substantially increasing the size and cost of the book, to assess the relative values of old and new data, and to enhance the quality of presentation by small-but important -modifications here and there, were tasks demanding a rare skill, a complete familiarity with current work, and meticulous care and patience. The authors have displayed all these qualities and qualifications, and they aro to be congratulated on bringing the valuable information of this well-established reference book up to date (references to publications early in 1950 are included) in such an acceptable manner and with such a surprisingly, but pleasantly, small increase in price of only eight shillings.

\section{Horned Beetles}

A Study of the Fantastic in Nature. By the late Gilbert J. Arrow. Edited by W. D. Hincks. Pp. viit $154+15$ plates. (The Hague : Dr. W. Junk, 1951.) 8.80 guilders.

C. J.ARROW, who died in 1948, had been on the J. staff of the British Museum (Natural History) for more than fifty years, studying Coleoptera, particularly the Lamellicornia. This book, which was virtually completed at the time of his death, deals with a subject by which he had long been fascinatedthe significance and origin of the fantastic horns that are so common in these and other beetles. It is a book in the Darwinian tradition : a closely woven argument supported by a wealth of illustrations from field observation and museum study.

These bizarre structures, whether gigantic mandibles or adventitious outgrowths of the head, thorax or limbs, present remarkable parallels with the horns and tusks of mammals. They are almost confined to the male, show great diversity of form and are rarely, if ever, employed as tools. Arrow rejects Darwin's theory of sexual selection and explains their existence on the basis of two classes of phenomena : the males do little useful work and so these useless or obstructive outgrowths are not curbed by natural selection; the excrescences are a product of increased bulk, since in a species or in a group they enlarge at a greater rate than the body as a whole. This thesis, when it is expressed in the terms of biometry, physiology and genetics, is one that will obtain wide support at the present time. 